\title{
Massive haemoperitoneum due to uterine artery erosion by endometriosis and a review of the literature
}

\author{
Paul Fiadjoe $\cdot$ Anne Thomas-Phillips $\cdot$ Kalpana Reddy
}

Received: 27 April 2007 / Accepted: 18 July 2007 /Published online: 16 August 2007

(C) Springer-Verlag 2007

\begin{abstract}
The aim of the literature review was to compile and compare similar cases of massive haemoperitoneum in an asymptomatic woman where the bleeding was from the right uterine artery, which had been eroded by pelvic endometriosis. To our knowledge this is the second case reported in the literature. Case reports of other sources of bleeding leading to haemoperitoneum were studied, comparisons were made, and the results compiled. Although several cases of massive haemoperitoneum have been reported, spontaneous bleeding from uterine artery erosion is a rare occurrence. The abdominal surgeon should be vigilant and alert to localise rare sites of bleeding. This literature review emphasises that endometriosis can present in many ways and a high level of clinical suspicion is necessary.
\end{abstract}

Keywords Haemoperitoneum · Subfertility · Laparoscopy · Laparotomy

Endometriosis is a gynaecologic condition affecting women of reproductive age, with an estimated prevalence of 3-10\% in the general population and of $25-35 \%$ in infertile women [1]. It is rare that it presents as an acute abdomen, and when

\section{P. Fiadjoe $(\bowtie)$}

St Michael's Hospital,

Southwell St,

Bristol BS2 8EG, United Kingdom

e-mail:kgabla@yahoo.com

\author{
A. Thomas-Phillips \\ Southmead Hospital, \\ Bristol, United Kingdom \\ K. Reddy \\ Cheltenham General Hospital, \\ Cheltenham, United Kingdom
}

it does it is usually due to ruptured endometriotic cyst. There are several cases of endometriosis causing hemoperitoneum. Here, we report a case of massive intra-abdominal haemorrhage from endometriosis eroding into the right broad ligament and uterine artery.

The patient is a 39-year-old woman with a known history of primary subfertility of 2 years duration. She had slightly irregular menstrual cycle with no history of dysmenorrhoea and dyspareunia. Investigations revealed anovulation. She was hence commenced on clomifene $50 \mathrm{mg}$ tablets to be taken between days 2 and 6 of her cycle. Simultaneously a hysterosalpingogram was arranged which revealed unilateral blocked fallopian tube. Hence the clomifene treatment was stopped and she was awaiting a diagnostic laparoscopy and dye test.

A month later she presented to the Accident and Emergency Department with 6 days' history of lower abdominal, right lower back and flank pain. This was associated with episodes of vomiting. She was then currently menstruating with no history of dysmenorrhoea. She was seen by the general surgical team whose examination revealed slight abdominal distension with generalised tenderness, but no acute signs of peritonism. She declined vaginal examination as she was menstruating. She was hemodynamically stable, but pyrexial of $38^{\circ} \mathrm{C}$.

Investigations revealed haemoglobin of $7.6 \mathrm{~g} / \mathrm{dl}$ and raised inflammatory markers. Abdominal and pelvic ultrasound confirmed fluid in the abdominal cavity with areas of mixed echogenicity on both sides of the uterus. She hence was transfused with 2 units of blood. She was reviewed by the gynaecology team who made a provisional diagnosis of a ruptured haemorrhagic ovarian cyst. Conservative management was originally planned, but as her condition deteriorated over $24 \mathrm{~h}$ she was subjected for a laparoscopy and laparotomy. 
Laparoscopy revealed hemoperitoneum of approximately 4.01 . She hence had a laparotomy which confirmed a ruptured right endometriotic cyst eroding into the broad ligament, pelvic side wall and the uterine artery. There was continuous bleeding from the ruptured uterine artery. The right fallopian tube was stuck and damaged; the left tube and ovary revealed inflammatory reaction from endometriosis and the rectum was stuck to the pouch of Douglas and back of the uterus with serosal damage.

Once haemostasis was achieved, help from the urologist and colorectal surgeon was solicited to ensure that the ureter and rectum were intact. We proceeded to perform a right salpingo-ophorectomy.

She was managed in ITU and had 6 units of packed cells and 4 units of FFP. She made an uneventful postoperative recovery and was discharged home on the 7 th day with a follow-up appointment at the fertility clinic to discuss her fertility options.

Endometriosis has the unique ability to infiltrate the walls of different structures like the bowel, bladder, uterosacral ligaments [4], broad ligaments [5], uterine cornua [3] and even ectopic endometrial tissue [5].

There have been several reports of endometriosis causing massive hemoperitoneum. For a review of Literature, see Table 1.

We report a case of massive and acute hemoperitoneun where the site of bleeding was from the right uterine artery, which had been eroded by pelvic endometriosis. A similar case has been reported [2], but our patient is different in that she had been asymptomatic.

Endometriosis has a distinct, cancer-like, invasive character that leads to fibrosis, scarring and occasional erosion through different structures, resulting in rectal bleeding, haemoptysis and haematuria [6]. It is well known that there is no correlation between the extent of pelvic endometriosis and symptomatology as patients with mild and minimal disease may be severely incapacitated, whereas patients with extensive disease may report a paucity of symptoms [1]. Even pregnant patients have not been spared, and several cases have been reported that presented with hemoperitoneum secondary to pelvic endometriosis $[9,10]$. This is contrary to common belief that pregnancy improves and may even cure endometriosis. Massive hemoperitoneum leading to preshock has also been reported as the first presenting symptom in two patients in whom there was no previous history suggestive of endometriosis [6].

Infertility is frequently associated with endometriosis. Another aspect to be kept in mind is that when these patients become pregnant by artificial reproductive treatments, spontaneous rupture of vessels can occur in pregnancy [10] All this goes to emphasise that endometriosis can present in different ways and a high level of clinical suspicion is necessary.

When a patient presents with hemoperitoneum leading to preshock, it may be difficult to localise the original site of bleeding. During laparotomy trauma due to manual exploration, blunt dissection, retraction and packing of the bowel will obscure the original bleeding source by producing many other bleeding areas [2]. However, we were able to pinpoint the origin of bleeding. The entire pelvis was unhealthy looking with clear endometriotic areas. Where did the disease actually originate and did it then erode into the right uterine artery? Or was there a rupture of an endometrioma that was impinging on the uterine artery? We do not know if there was endometriosis in the pelvic side wall and broad ligament which could have infiltrated the ovary leading to an endometrioma or if it was an endometrioma which infiltrated into the broad ligament. However, histological examination confirmed endometriosis in the ovarian tissue with no evidence of malignant change.

Table 1 On compiling reports of hemoperitoneum

\begin{tabular}{|c|c|c|}
\hline Author, year, reference & Source of bleeding & Unusual salient points \\
\hline Thomas et al, 2002, [2] & Rupture of uterine artery & Stage 3 endometriosis, primary infertility \\
\hline Uri et al, 1979, [3] & Cornual rupture & $\begin{array}{l}\text { Lap. sterilisation by diathermy } 6 \text { years } \\
\text { previously }\end{array}$ \\
\hline Ranney, 1970, [4] & $\begin{array}{l}\text { Pelvic endometriotic implants, ruptured endometriotic cyst, } \\
\text { ovarian implants }\end{array}$ & Several different sites, 6 patients \\
\hline $\begin{array}{l}\text { Carmichael \& Williams, } \\
\text { 1972, [5] }\end{array}$ & Erosion of ectopic endometrial tissue & Ulcerated area on broad ligament \\
\hline Harmanli et al, 1998, [6] & Fallopian tube & No previous endometriosis \\
\hline Kumar, 1996, [7] & Endometriotic peritoneal deposits & Earlier normal laparoscopy, on COCs \\
\hline Fujino et al, 1992, [8] & Uterine serosal surface & Uterine adenomyosis \\
\hline Ismail et al, 1999, [9] & Raw area on posterior aspect of uterus & $\begin{array}{l}\text { Pelvic endometriosis in pregnancy: } 2 \\
\text { patients }\end{array}$ \\
\hline Mizumoto et al, 1996, [10] & Spontaneous rupture of uterine vessels & $\begin{array}{l}\text { Pregnancy complicated by endometriosisa: } 5 \\
\text { patients }\end{array}$ \\
\hline
\end{tabular}


In any instance this and similar cases emphasise that the abdominal surgeon must be vigilant and alert always so as not to overlook rare sources of bleeding.

\section{References}

1. Speroff L, Glass RH, Kase NG (1994) Endometriosis. In: Mitchell C (ed) Clinical gynaecologic endocrinology and infertility. Williams and Wilkins, Baltimore, pp 853-872

2. Thomas I, Janicki MD, Laura J, David MD, Rana S (2002) Massive and acute hemoperitoneum due to rupture of the uterine artery by erosion from an endometriotic lesion. Fertil Steril 78(4):879-881

3. Uri FI, Opaneye A (1979) Hemoperitoneum due to corneal endometriosis after laparoscopic sterilization. British $\mathrm{J}$ of Obstet \& Gynecol 86:664-665
4. Ranney B (1970) Endometriosis, Emergency operations due to hemoperitoneum. Obstet Gynecol 36:437-442

5. Carmichael JL, Williams DB (1972) Hemoperitoneum from erosion of ectopic endometrial tissue. South Med J 65:371-372

6. Harman OH, Chastain A, Cay JG (1993) Massive hemoperitoneum from endometriosis of the fallopian tube. J Reprod Med 43:716-718

7. Kumar S (1996) Acute massive hemoperitoneum due to mild pelvic endometriosis. Aust NZ J Obstet Gynecol 36(4):490-491

8. Fujino T, Wantanabe T, Shinmura R, Hahn L, Nagata Y, Hasui K (1992) Acute abdomen due to adenomyosis of the uterus. AsiaOceania J Obstet Gynecol 18:333-337

9. Ismail KMK, Shervington J (1999) Hemoperitoneum secondary to pelvic endometriosis in pregnancy. Int J Obstet Gynecol 67:107-108

10. Mizumoto Y, Furuya K, Kikuchi Y, Aida S, Hyakutake K, Tamai S, Nagata I (1996) Spontaneous rupture of the uterine vessels in a pregnancy complicated by endometriosis. Acta Obstet Gynecol Scand $75: 860-862$ 